This article was downloaded by: [University of Toronto]

On: 14 October 2008

Access details: Access Details: [subscription number 776112710]

Publisher Psychology Press

Informa Ltd Registered in England and Wales Registered Number: 1072954 Registered office: Mortimer House, 37-41 Mortimer Street, London W1T 3JH, UK

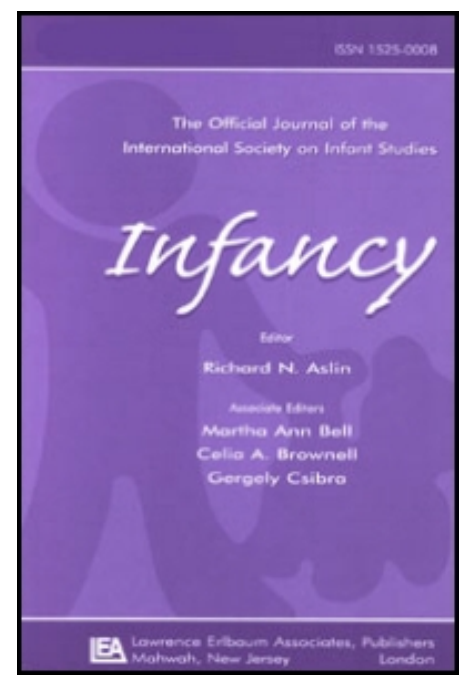

Infancy

Publication details, including instructions for authors and subscription information:

http://www.informaworld.com/smpp/title content=t775653654

\title{
Clause Segmentation by 6-Month-Old Infants: A Crosslinguistic Perspective
}

Elizabeth K. Johnson a; Amanda Seidl b

${ }^{a}$ Department of Psychology, University of Toronto, ${ }^{b}$ Department of Speech, Language and Hearing

Sciences, Purdue University,

Online Publication Date: 01 September 2008

To cite this Article Johnson, Elizabeth K. and Seidl, Amanda(2008)'Clause Segmentation by 6-Month-Old Infants: A Crosslinguistic Perspective',Infancy, 13:5,440 - 455

To link to this Article: DOI: $10.1080 / 15250000802329321$

URL: http://dx.doi.org/10.1080/15250000802329321

\section{PLEASE SCROLL DOWN FOR ARTICLE}

Full terms and conditions of use: http://www.informaworld.com/terms-and-conditions-of-access.pdf

This article may be used for research, teaching and private study purposes. Any substantial or systematic reproduction, re-distribution, re-selling, loan or sub-licensing, systematic supply or distribution in any form to anyone is expressly forbidden.

The publisher does not give any warranty express or implied or make any representation that the contents will be complete or accurate or up to date. The accuracy of any instructions, formulae and drug doses should be independently verified with primary sources. The publisher shall not be liable for any loss, actions, claims, proceedings, demand or costs or damages whatsoever or howsoever caused arising directly or indirectly in connection with or arising out of the use of this material. 


\title{
Clause Segmentation by 6-Month-Old Infants: A Crosslinguistic Perspective
}

\author{
Elizabeth K. Johnson \\ Department of Psychology \\ University of Toronto \\ Amanda Seidl \\ Department of Speech, Language and Hearing Sciences \\ Purdue University
}

\begin{abstract}
Each clause and phrase boundary necessarily aligns with a word boundary. Thus, infants' attention to the edges of clauses and phrases may help them learn some of the language-specific cues defining word boundaries. Attention to prosodically wellformed clauses and phrases may also help infants begin to extract information important for learning the grammatical structure of their language. Despite the potentially important role that the perception of large prosodic units may play in early language acquisition, there has been little work investigating the extraction of these units from fluent speech by infants learning languages other than English. We report 2 experiments investigating Dutch learners' clause segmentation abilities. In these studies, Dutch-learning 6-month-olds readily extract clauses from speech. However, Dutch learners differ from English learners in that they seem to be more reliant on pauses to detect clause boundaries. Two closely related explanations for this finding are considered, both of which stem from the acoustic differences in clause boundary realizations in Dutch versus English.
\end{abstract}

One of the primary tasks faced by young language learners is the job of parsing the speech signal into linguistically relevant units, or clauses, phrases, and words (Jusczyk, 1997; Saffran, Werker, \& Werner, 2006). The left edge of clauses and phrases coincide with word onsets and the right edge of clauses and phrases coin-

Correspondence should be sent to Elizabeth K. Johnson, Department of Psychology, University of Toronto Mississauga, 3359 Mississauga Road North, Room 4071, CCT, Mississauga, ON, Canada, L5L IC6. E-mail: elizabeth.johnson@utoronto.ca 
cide with word offsets. Thus, infants could learn some of the characteristics marking the edges of smaller units (i.e., words) by paying attention to the edges of larger syntactic units (specifically large prosodic units such as utterance or intonational phrase boundaries coincident with large syntactic units such as phrases and clauses; Jusczyk, 1997). If this is the case, then understanding how infants perceive large syntactic boundaries is fundamental to understanding how infants learn to segment words from speech. Infants' ability to extract large prosodically wellformed units from speech may also play an important role in bootstrapping the grammatical structure of language (e.g., Morgan \& Demuth, 1996, for a discussion of prosodic bootstrapping).

Large prosodic units are good candidates for helping infants begin to learn about the language-specific sound structure of their language because infants are attentive to these junctures from very early on (Christophe, Mehler, \& Sebastián-Gallés, 2001). By 6 months, English learners use their sensitivity to acoustic cues aligned with clause and phrase boundaries to package and recognize linguistically relevant units in fluent speech (Nazzi, Kemler Nelson, Jusczyk, \& Jusczyk, 2000; Soderstrom, Seidl, Kemler Nelson, \& Jusczyk, 2003; Soderstrom, Kemler Nelson, \& Jusczyk, 2005; see also Schmitz, Höhle, \& Weissenborn, 2003, for German data). Using the headturn preference procedure (HPP), Nazzi et al. (2000; see also the Seidl's 2007 replication of this study) familiarized English learners with the same sequence of words produced in one of two ways. In a prosodically well-formed version, the sequence of words was produced as a complete clause (e.g., rabbits eat leafy vegetables). In a prosodically ill-formed version, the same sequence of words spanned a boundary between two clauses (e.g., . . rabbits eat. Leafy vegetables ... extracted from a longer utterance containing two well-formed clauses). Following familiarization with the two versions of the same word sequence (clause and nonclause), infants were tested on their listening preference for passages containing the well-formed clausal sequence versus passages containing the ill-formed nonclausal sequence. Six-month-old English-learning infants listened significantly longer to the passage containing the well-formed clause, despite the fact that both passages contained equally familiar word strings. This finding indicates that the 6-month-olds package the incoming speech stream into prosodically well-formed clauses and show what is essentially a familiarity preference for multiword strings that adults judge as coherent groupings. Subsequent studies have replicated these findings with smaller prosodic junctures (noun and verb phrases; Soderstrom et al., 2003), although there was some indication that 6-month-olds' ability to extract phrases from speech was not always as robust as their ability to extract clauses.

Because English learners typically do not segment English words from speech before 7.5 months of age (Jusczyk \& Aslin, 1995; however, see Bortfeld, Morgan, Golinkoff, \& Rathbun, 2005, for an exceptional case), the finding that 6-month-olds package the speech stream into clauses and phrases is consistent with the notion that infants tend to segment large prosodic units (clauses marked by major prosodic phrase boundaries) 
first, and then work their way down the Prosodic Hierarchy (Selkirk, 1984) to smaller units (small phrase boundaries and words; see Johnson, 2008). This in turn supports the notion that infants learn some of the language-specific cues marking word and phrase boundaries by first noting the acoustic properties characterizing the edges of clausal units (Kemler Nelson, Hirsh-Pasek, Jusczyk, \& Wright-Cassidy, 1989). Additional support for this view comes from work showing that older infants use large prosodic junctures, such as clauses and phrases, to help them spot word boundaries (Gout, Christophe, \& Morgan, 2004; Seidl \& Johnson, 2006, 2008).

Infants' attention to the edges of large prosodic units could help them learn the cues marking phrase and word boundaries. For example, in English, the phone [?] occurs word finally but not word initially. Likewise, the phoneme $[\mathrm{h}]$ occurs word initially but not word finally. Because the edges of large prosodic boundaries necessarily align with word boundaries, infants could learn about the possible positioning of these phones by attending to clause onsets and offsets; that is, infants could learn that [?] never marks the onset of a linguistically relevant unit and $[\mathrm{h}]$ never marks the offset. This information could in turn be used to spot phrase and word boundaries embedded in the middle of long utterances. A similar strategy could be used to learn about subphonemic cues to word boundaries. In English, stop consonants tend to have a longer voice onset time (VOT) when they occur at large (phrase) as opposed to weak (word or syllable) boundaries (e.g., Fougeron \& Keating, 1997). The situation is the reverse for Dutch, where stop consonants have a shorter VOT when a boundary is stronger (Cho \& McQueen, 2005). Thus, VOT represents a language-specific cue to phrase and word boundaries. Dutch infants could learn that the VOTs of certain phonemes tend to be shorter in clause-initial position than in clause-medial position. This realization could be used to infer that relatively shortened VOTs tend to signal the onset of smaller linguistic units such as words.

Given the potentially important role that infants' sensitivity to large prosodic junctures may play in early word segmentation skills, it is surprising that little work has been done looking at the detection of large prosodic units cross-linguistically. In this paper, we begin to address this issue by testing Dutch infants' ability to extract clauses from speech. This question is interesting for many reasons, not the least of which is the time course of language development in Dutch- versus English-learning infants.

It has been shown that Dutch learners begin segmenting words from speech about 2 months later than English learners (Houston, Jusczyk, Kuijpers, Coolen, \& Cutler, 2000; Kooijman, Johnson, \& Cutler, 2008; Kuijpers, Coolen, Houston, \& Cutler, 1998). ${ }^{1}$ Differences in the acoustic realization of stress in Dutch versus

\footnotetext{
${ }^{1}$ It is unlikely that these results can be dismissed as differences in testing procedures between Dutch and American labs because all of these Dutch segmentation studies involved an exchange of researchers between labs to ensure that the testing booth and procedures were as closely matched as possible between labs. The same precautions were taken in the experiments reported in this article.
} 
English provide a possible explanation for this finding (see Kuijpers et al., 1998, for discussion). However, intonation differences between Dutch and English provide an additional possible explanation. Dutch has a narrower pitch range relative to English (Willems, 1982), leading Dutch speakers speaking English to sound (to English speakers) as if they have a relatively flat affect (Collins \& Mees, 1981). These prosodic differences between Dutch and English may be even more exaggerated in infant-directed speech because middle-class American mothers tend to modify the prosody of the utterances they address to infants more than mothers of other cultures (Fernald \& Kuhl, 1987). Many studies have shown suprasegmental cues, such as pitch movement, can facilitate word segmentation in infants as well as adults (Nazzi, Dilley, Jusczyk, Shattuck-Hufnagel, \& Jusczyk, 2006; Seidl \& Johnson, 2008; Shukla, Nespor, \& Mehler, 2006; Theissen, Hill, \& Saffran, 2005). This same information also appears to be important in early clause segmentation (Seidl, 2007). Thus, it is possible that the intonation differences between English and Dutch may contribute to a delay in Dutch learners' ability to segment clauses and phrases from speech. If infants learn word segmentation cues by attending to clause and phrase boundaries, then a delay in segmenting clauses and phrases from speech could lead to a delay in segmenting words from speech.

In this study, we have two goals. First, we ask whether Dutch-learning 6month-olds behave like English-learning 6-month-olds in that they use prosodic information to package fluent speech into linguistically well-formed units. Second, we ask if Dutch learners use the same acoustic cues as English learners to extract clauses from speech. More specifically, we test whether Dutch learners are like English learners in that they can detect clause boundaries even when the silences aligned with these junctures are absent.

\section{EXPERIMENT 1}

In this study we use the same procedure and design as Nazzi et al. (2000), Seidl (2007), and Soderstrom et al. (2003) to ask whether Dutch-learning 6-month-olds, like English-learning 6-month-olds, use prosodic information to package fluent speech into linguistically relevant units. Specifically, Dutch-learning 6-montholds were familiarized for a minimum of $30 \mathrm{sec}$ to each of two recordings of the same sequence of words: one prosodically well-formed and one prosodically illformed. Following this familiarization, infants were presented with two test passages. One passage contained the well-formed version of the familiarized word string and the other contained the ill-formed version. Note that both passages contained equally familiar word strings, but in one case the sequence spans a clause boundary and in one case it does not. We predicted that if Dutch-learning 6month-olds, like English-learning 6-month-olds, use prosodic information to rec- 
ognize clauses in fluent speech, they would listen significantly longer to the passage containing the well-formed as opposed to ill-formed clause.

\section{Method}

Participants. Thirty-six Dutch-learning 6-month-olds from the Nijmegen region were tested (23 girls). The infants were approximately 6 months old, with a mean age of 186 days (range $=171-198)$. The data from 8 additional infants were excluded due to fussiness $(n=6)$, mean looking times greater than $2.5 S D$ from the mean $(n=1)$, or experimenter error $(n=1)$. Parental consent was obtained for all participants.

Stimuli. Two passages were recorded in an infant-directed register by a Dutch-speaking female naive to the purpose of the study (see Appendix). Passage $1(6,440 \mathrm{msec})$ contained a prosodically well-formed version of the word sequence koude pizza smaakt niet zo goed, 'cold pizza doesn't taste so good,' and a prosodically ill-formed version of the word sequence de jongens eten koude pizza, 'the boys ate cold pizza.' Passage $2(6,600 \mathrm{msec})$ contained a prosodically wellformed version of the word sequence de jongens eten koude pizza, and a prosodically ill-formed version of the sequence koude pizza smaakt niet zo goed. For the purposes of this study, a prosodically ill-formed sequence of words refers to a sequence of words containing an intervening intonational phrase boundary. The four target word sequences were spliced from the passages for use as familiarization stimuli (see Table 1). The full passages were retained for use in the test phase.

Design. Half of the infants were assigned to Group A and familiarized with two different versions (both a clausal and nonclausal) of koude pizza smaakt niet zo goed. The other half were assigned to Group B and familiarized with two different

TABLE 1

Acoustic Cues in the Dutch Familiarization Stimuli

\begin{tabular}{llllll}
\hline & \multicolumn{2}{c}{ Group A } & & \multicolumn{2}{c}{ Group B } \\
\cline { 2 - 3 } \cline { 5 - 6 } \cline { 5 - 6 } & Within Clause & Clause Boundary & & Within Clause & Clause Boundary \\
\hline $\begin{array}{l}\text { Acoustic correlate } \\
\begin{array}{c}\text { Final full vowel } \\
\text { (pizza/eten) }\end{array}\end{array}$ & $\begin{array}{c}\text { [..pizza smaakt..] } \\
71 \mathrm{msec}\end{array}$ & pizza] [smaakt... & & [..eten koude..] & eten] [koude... \\
$\begin{array}{c}\text { Pause duration } \\
\text { (for Experiment } 1\end{array}$ & $0 \mathrm{msec}$ & $630 \mathrm{msec}$ & & $176 \mathrm{msec}$ & $201 \mathrm{msec}$ \\
$\begin{array}{c}\text { Pitch reset) } \\
\text { (change in f0 at } \\
\text { juncture) }\end{array}$ & $-27 \mathrm{~Hz}$ & & & $73 \mathrm{msec}$ & $820 \mathrm{msec}$ \\
\hline
\end{tabular}


versions (both clausal and nonclausal) of de jongens eten koude pizza. It was necessary to have two groups for a few reasons. First, having two separate sentences enables us to control for an unexpected preference for one particular production of the sentences and for one clause having more or stronger clause edge-marking cues. Second, and more important, in this crossed design both groups of infants are tested on the same passages, yet we expect a different preference pattern for each group because the familiarized clause and nonclause for Group A are in the opposite passage than the familiarized clause and nonclause for Group B. All infants were tested using the HPP.

Procedure and Apparatus. In the HPP, the infant sits on a caregiver's lap on a chair in the center of a three-sided booth. At the start of a given trial a green light on the front panel begins to flash. When the infant orients to the front, a red sidelight will begin to flash. When the infant turns his or her head toward that light, speech begins to play, and continues to play until the infant looks away for more than 2 consecutive sec. A button box is connected to a computer that controls the presentation of stimuli and records the looking time to each stimulus (the dependent measure). Both caregiver and experimenter wear sealed headphones and listen to masking music throughout the experiment.

In the familiarization phase for this experiment, speech was presented until the infant reached a listening time criterion (in this case, $30 \mathrm{sec}$ to each of the two familiarization sequences). When the infant looked away for more than $2 \mathrm{sec}$, the sound file stopped once the next pause between the repetitions of the sequence was reached; that is, the familiarization stimuli never cut off in the middle of a word sequence. In the test phase the two passages were presented: During half of the trials the passage containing the well-formed version of the familiarized word sequence was presented, and during the other half of the trials the passage containing the ill-formed version was presented. There were 12 trials presented in three blocks, with trial order randomized within each block.

\section{Results and Discussion}

Mean orientation times to the test passage containing the well-formed sequence and the test passage containing the ill-formed sequence were calculated for each of the 36 participants (see Figure 1). Twenty-six out of 36 of the infants tested listened longer to the passage containing the well-formed sequence $(M=10.47, S D=$ 4.7) than to the passage containing the ill-formed sequence $(M=8.9, S D=4.2)$. A sign test indicated that the number of infants who listened longer to the wellformed passages was greater than chance performance would predict, $p=.01$. A 2 (familiarization group: A vs. B) $\times 2$ (test passage type: well-formed vs. ill-formed) mixed design analysis of variance (ANOVA) revealed a main effect of test passage type, $F(1,34)=8.6, p=.006$, but no main effect of familiarization group, $F(1,34)$ 


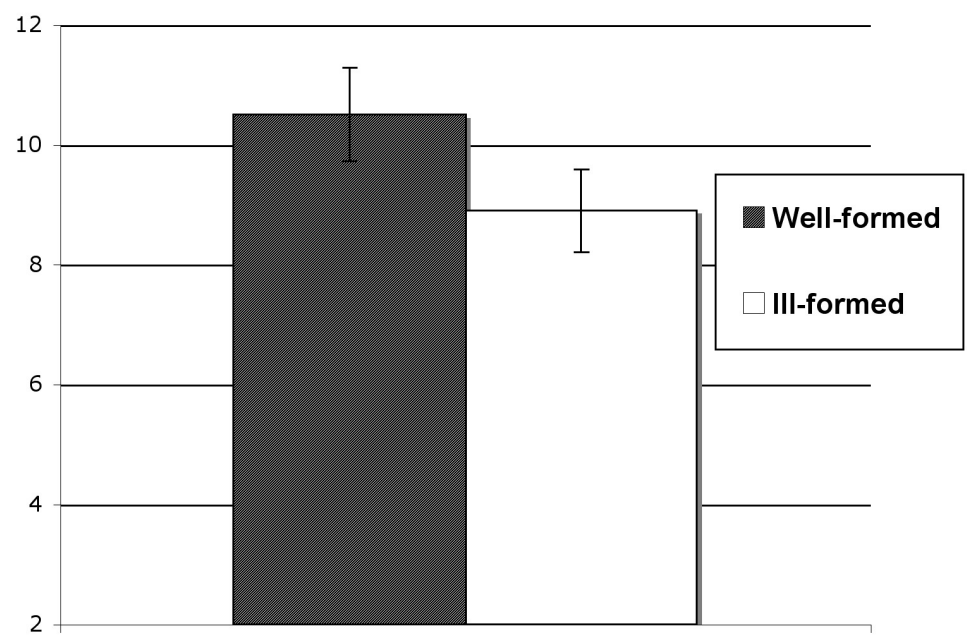

FIGURE 1 Mean length of look to well- and ill-formed passages in seconds for Experiment 1 (error bars indicate $S E$ ).

$=1.4, p=.24$, or Familiarization Group $\times$ Test Passage Type interaction, $F(1,34)<$ 1 . The main effect of test passage type fell in the upper range of a medium-sized effect $(d=.78)$

These results extend the findings of Nazzi et al. to a new language learning population (see also Schmitz et al., 2003), and also suggest that Dutch learners' delay in beginning to segment words from speech is not likely to be due to a clear delay in segmenting clauses from speech. ${ }^{2}$ Do these results suggest that there are no differences in Dutch- and English-learning infants' sensitivity to clause boundaries? If this were the case, one would expect Dutch- and English-learning infants to use similar strategies to extract clauses from speech. English learners are so sensitive to clause boundaries, that, like adult native speakers (Aasland \& Baum, 2003), they are able to detect them even when only a subset of the cues to clause boundaries are present, for example, when the pauses at clause boundaries are neutralized either through deletion of pauses between clauses or through insertion of pauses within clauses (Seidl, 2007). Findings from Seidl's study suggest that English learners have a robust sensitivity to clause boundaries, using multiple redundant cues to detect these junctures without relying heavily on pause.

\footnotetext{
${ }^{2}$ As pointed out by an anonymous reviewer, we cannot be sure whether or not clause segmentation is delayed without determining the onset of clause segmentation in both languages. Nonetheless, our results demonstrate that Dutch learners are segmenting clauses from speech well before 7.5 months of age. Thus, the results of Experiment 1 do not provide evidence for the hypothesis that a delay in clause segmentation underlies Dutch learners' delay in segmenting words from speech.
} 
In Experiment 2, we ask if Dutch learners are able to detect clause boundaries when the silence (or lack of silence) marking the presence (or absence) of a clause boundary is removed. As demonstrated in Table 1, the stimuli we used in Experiment 1 contained many redundant cues to clause boundaries aside from pause. Thus, one might predict that, if they are not delayed with respect to clause segmentation ability, the Dutch-learning infants will perform like their age-matched English-learning counterparts; that is, they will detect clause boundaries even when the pause information indicating a clause juncture is neutralized. Then again, pitch resets (large pitch changes at intonational phrase boundaries) provide English learners with an important cue to clause boundaries, and Dutch tends to have smaller pitch resets than English. Indeed, the clause boundary pitch resets in the stimuli used in Seidl's English studies (see Table 2) are nearly two times greater in magnitude than those used in this study. Given the smaller pitch resets in the Dutch recordings it may be difficult for Dutch infants to segment the clauses from speech when the pauses marking the clause boundaries are removed. A related, yet differentiable, reason to predict that Dutch infants may rely more heavily on pauses to detect clauses is attunement to cue weighting in the ambient language. It has been suggested that adult Dutch speakers rely more heavily on pause than their English-speaking counterparts (Sanderman \& Collier, 1997). If 6-month-old Dutch infants have learned this language-specific weighting (see Friederici, Friedrich, \& Christophe, 2007, for evidence that infants tune into language-specific prosodic patterns exceptionally early), then they may fail to detect clause boundaries when they are not marked by pauses. For these two reasons, one might predict that Dutch learners would have more difficulty than English learners in detecting clause boundaries in their native language when the pauses occurring at clause junctures are neutralized.

\section{EXPERIMENT 2}

In this experiment, we manipulated the familiarization sequences used in Experiment 1 in two ways. In the pause-deletion condition, we deleted the silence occur-

TABLE 2

Acoustic Cues in the English Familiarization Stimuli

\begin{tabular}{|c|c|c|c|c|}
\hline \multirow[b]{2}{*}{ Acoustic Correlate } & \multicolumn{2}{|c|}{ Group A (Leafy) } & \multicolumn{2}{|c|}{ Group B (Rabbits) } \\
\hline & Within Clause & Clause Boundary & Within Clause & Clause Boundary \\
\hline Word sequence & $\begin{array}{c}{[\ldots \text { vegetables }} \\
\text { taste } \ldots . .]\end{array}$ & $\begin{array}{c}\text {... vegetables] } \\
\text { [taste.... }\end{array}$ & $\begin{array}{l}{[\ldots \text { eat leafy }} \\
\ldots .]\end{array}$ & ... eat] [leafy ... $]$ \\
\hline Nucleus duration & $12 \mathrm{msec}$ & $210 \mathrm{msec}$ & $120 \mathrm{msec}$ & $240 \mathrm{msec}$ \\
\hline Pause duration & $50 \mathrm{msec}$ & $380 \mathrm{msec}$ & $30 \mathrm{msec}$ & $300 \mathrm{msec}$ \\
\hline Change of pitch & $+68 \mathrm{~Hz}$ & $+233 \mathrm{~Hz}$ & $+47 \mathrm{~Hz}$ & $+244 \mathrm{~Hz}$ \\
\hline
\end{tabular}


ring at the clause boundary of the ill-formed familiarization sequence while leaving the well-formed sequence intact (also lacking a pause in the same location). In the pause-insertion condition, we inserted a silence in the middle of the wellformed familiarization sequence while leaving the ill-formed sequence (with an existing pause in the same location) untouched. We performed both manipulations because this allowed us to address two slightly different questions. By deleting the pause marking the clause boundary in the ill-formed utterance, we created an utterance containing conflicting cues to the presence or absence of an intervening clause boundary: The lack of the pause suggested that no boundary was present, whereas all other cues marking the boundary (e.g., preboundary lengthening, pitch reset, etc.) remained. If infants still perceive ill-formed clauses as ill formed despite the absence of a silence marking the clause juncture, this suggests that the other cues marking the juncture are adequate to indicate the presence of a boundary; that is, pauses are not necessary cues to clause boundaries. Alternatively, if after this pause-deletion manipulation infants now perceive the ill-formed clause as well formed, this suggests that the infants tested in Experiment 1 were relying heavily on the pause to detect the clause boundary. By adding a pause in the well-formed utterance, we once again created stimuli containing conflicting cues to the presence or absence of the boundary: The presence of a pause suggested that a boundary was present, whereas all other cues that would be expected to mark a clause boundary were absent. Thus, from the infants' perspective, both of these manipulations neutralize the pause information that indicates which of the two familiarization strings is well-formed and which is ill-formed. In the pause-deletion condition, we neutralize the pause information by deleting the pause in the ill-formed utterance (possibly making the ill-formed utterance sound more well formed). In the pause-insertion condition, we neutralize the pause information by inserting a pause in the well-formed clause (thus making the well-formed utterance sound less well formed). When tested on English passages edited in the same fashion, English-learning 6-month-olds have been shown to segment the clause in both the pause-deletion and pause-insertion conditions (Seidl, 2007). This finding demonstrated that pitch and preboundary length cues to boundaries are sufficient to cause English learners to perceive a clause-like prosodic boundary and that pause is not a necessary cue in and of itself. If Dutch learners (like English learners) do not treat the silence occurring at the juncture between two clauses as a necessary cue to detect a clause boundary, then they should behave as the English learners did in Seidl (2007); that is, they should look longer to the familiarized well-formed string of words in both the pause-deletion and pause-insertion condition.

\section{Method}

Participants. Thirty-six Dutch-learning 6-month-olds from the Nijmegen region were tested (16 girls). The infants were approximately 6 months old, with a 
mean age of 182 days (range $=168-195$ ). The data from 9 additional infants were excluded due to fussiness $(n=5)$, disinterest in the lights $(n=2)$, mean looking times greater than $2.5 S D$ from the mean $(n=1)$, or parental interference $(n=1)$. Parental consent was obtained for all participants.

Stimuli. In the pause-deletion familiarization stimuli, the pause at the clause juncture in the ill-formed sequence was reduced (or deleted) to match the duration of the pause (or lack of pause) in the corresponding well-formed word sequence (resulting in a pause $73 \mathrm{msec}$ long between the words eten and koude in the de jongens eten koude pizza sequence, and a $0 \mathrm{msec}$ pause between the words pizza and smaakt in the koude pizza smaakt niet zo goed sequence). In the pause-insertion familiarization stimuli, the well-formed sequence was altered by adding a silence at the point where the clause juncture occurred in the ill-formed sequence (e.g., a pause was inserted between the words eten and koude in the well-formed version of the sequence de jongens eten koude pizza). The duration of the inserted pause was equal to the mean length of the pause occurring in the two ill-formed sequences $(738 \mathrm{msec})$. The same unedited test passages were used as in Experiment 1.

Design. Half of the infants were assigned to the pause-inserted condition and half of the infants were assigned to the pause-deleted condition. Within each of these groups, half of the infants were familiarized to two versions of the word sequence de jongens eten koude pizza, and half of the infants were familiarized to two versions of the word sequence koude pizza smaakt niet zo goed.

Procedure and apparatus. The same procedure and apparatus was used as in Experiment 1.

\section{Results and Discussion}

Mean orientation times to the passage containing the well-formed sequence and the passage containing the ill-formed sequence were calculated for each of the 36 participants (see Figure 2). Eighteen of the 36 infants listened longer to the passage containing the well-formed sequence $(M=9.15, S D=4.4)$ than to the passage containing the ill-formed sequence $(M=9.03, S D=3.6)$. This was not significant by a sign test, $p>.1$. A 2 (familiarization group: A vs. B) $\times 2$ (test passage type: well formed vs. ill formed) $\times 2$ (neutralization condition: pause insertion vs. pause deletion) mixed design ANOVA revealed no main effect of test passage type, $F(1,32)<1$; familiarization group, $F(1,32)<1$; or neutralization condition, $F(1,28)<1$. Additionally, no interactions were significant. Finally, an effect size analysis indicated that the $.12 \mathrm{sec}$ longer looking time to well-formed over ill-formed passages was not likely to indicate a meaningful trend $(d=.06)$. 


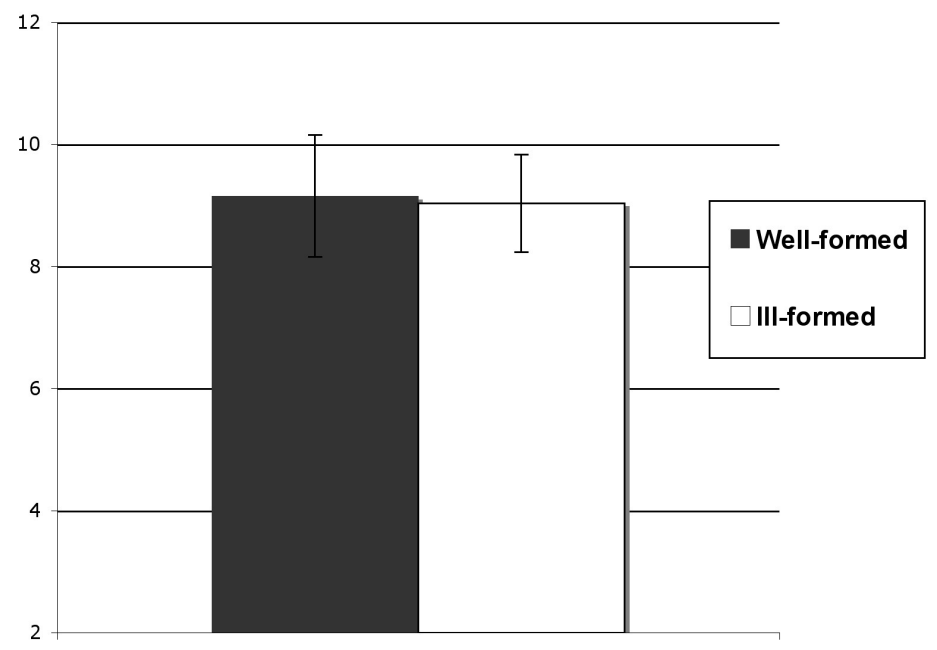

FIGURE 2 Mean length of look to well- and ill-formed passages in seconds for Experiment 2 (error bars indicate $S E$ ).

An ANOVA with looking time difference scores (looking time to well-formed passage minus looking time to ill-formed clause) as a dependent measure and experiment ( 1 or 2$)$ as a between-subject factor revealed that there was a significant effect of experiment on looking time difference scores, $F(1,70)=3.99, p=.05$. This effect was driven by greater looking time difference scores in Experiment 1 $(M=1.48 \mathrm{sec})$ than Experiment $2(M=.12 \mathrm{sec})$. These results demonstrate that the infants tested in Experiment 1 were behaving differently than those tested in Experiment 2, a difference due to larger difference scores in Experiment 1 than in Experiment 2 (note that the larger the difference score, the stronger the evidence that infants can segment clauses from speech). A similar analysis was carried out comparing the results obtained in Experiment 2 of Seidl (2007) to the data collected in Experiment 2 of this study. Note that Experiment 2 of Seidl (2007) differed from that of this article only in that Seidl tested English-learning infants on English with pauses at boundaries neutralized, whereas this study tested Dutch-learning infants on Dutch with the pauses at boundaries neutralized. An ANOVA with difference scores (looking time to well-formed passage minus looking time to ill-formed clause) as a dependent measure and language group (Dutch, English) as a between-subject factor revealed an effect of language, $F(1,59)=3.05, p<.003$. This effect was driven by greater looking time differences in the study with English-learning infants $(M=3.5 \mathrm{sec})$ than the study with Dutch-learning infants $(M=.12 \mathrm{sec})$, indicating that the English-learning infants tested in Seidl (2007) performed differently than the Dutch-learning infants tested in this study; that is, Dutch-learning infants differ 
from English-learning infants in that they appear to be reliant on pauses to detect clause boundaries. ${ }^{3}$

\section{GENERAL DISCUSSION}

Clause and phrase boundary perception may play an important role in both early word segmentation and syntactic structure acquisition. Despite the potential importance of these large prosodic units in early language acquisition, little work has been done to examine how infants learning languages other than English use these boundaries to package speech. This study represents an important first step toward understanding early clause segmentation from a cross-linguistic perspective.

In Experiment 1 we found that Dutch-learning 6-month-olds, much like their age-matched English-learning counterparts, use their sensitivity to clause junctures to help them package and process the speech signal. However, in Experiment 2, Dutch learners differed from English learners in that they were unable to detect clause boundaries when the pauses marking these boundaries were neutralized. Why are Dutch learners unable to detect a clause boundary when the pause marking the boundary is neutralized? There are two likely explanations. One explanation involves differences in clause segmentation strategies between Dutch- and English-learning infants. The other explanation involves differences in saliency of the clause boundaries in the stimuli used in this versus those used in Seidl's English study.

The first explanation focuses on differences between the two infant populations we tested; that is, that Dutch- and English-learning infants may differentially rely on pauses as cues to word boundaries. Because English has a wider pitch range than Dutch, English listeners may learn to detect clause junctures by attending primarily to pitch cues. Dutch listeners, on the other hand, may attend more heavily to pause cues. If this were the case, then the Dutch 6-month-olds tested in Experiment 2 may have failed to detect clause boundaries in the absence of pause cues because they have already developed language-specific clause segmentation procedures. Adult studies suggesting that Dutch adults seem to rely heavily on pause cues to detect clause boundaries provide some support for this hypothesis (Sanderman \& Collier, 1997).

\footnotetext{
${ }^{3}$ As pointed out by an anonymous reviewer, an alternative explanation is that Dutch learners failed to recognize the pause-edited stimuli because when we removed or added a pause to the familiarization utterances, we reduced the similarity between the familiarization and test stimuli. However, we find this explanation alone to be unlikely given that the English learners had no trouble recognizing the similarity between the pause-edited familiarization utterances and the unedited test utterances (see Seidl, 2007).
} 
The second explanation is that all 6-month-olds may have a universally similar strategy for detecting clause boundaries; however, the clause boundaries in the Dutch stimuli we used in this study were not as saliently marked as those in the English stimuli used by Seidl (2007). Indeed, in support of this interpretation, the pitch resets in Seidl's study were nearly twice as large as those used in the Dutch stimuli in this study. However, as we noted in the introduction, Dutch has a smaller intonation range than English (Collins \& Mees, 1981; Willems, 1982). It is therefore not surprising that our stimuli reflect this fact. The smaller pitch resets we see in our stimuli are characteristic of Dutch. ${ }^{4}$ Perhaps the Dutch infants we tested in Experiment 2 failed to segment the clauses when the pause information was neutralized simply because the pitch resets and vowel lengthening at the clause boundaries were not strong enough to cue the boundary on their own. If this were the case, then this would suggest that, in general, Dutch-learning infants might initially have a difficult time with boundaries that are most often not marked by pauses, such as phrase boundaries. Thus it could be possible Dutch learners' delay in solving the word segmentation problem is causally linked to the size of pitch resets in Dutch.

Which explanation is more likely? Did the Dutch-learning 6-month-olds tested in Experiment 2 fail to properly extract clauses from speech because the Dutch speech materials we used did not contain strongly pitch-marked clause boundaries? Or did their failure reflect an attunement to the cues that are most heavily weighted by adult Dutch speakers for detecting clause junctures in Dutch? These two explanations are difficult to disentangle due to the language confound inherent in our crosslinguistic comparison (i.e., the Dutch infants were tested on Dutch, whereas the American infants were tested on English). Thus, the results of Experiments 1 and 2 alone do not allow us to determine how to best account for these data. In a follow-up study (Johnson \& Seidl, 2005), we attempted to address this issue by testing Dutch-learning 6-month-olds on the English stimuli, and English-learning infants on the Dutch stimuli. Unfortunately, neither group of infants succeeded in segmenting clauses from the passages in a nonnative language and it is not clear whether this null result was due to cue strength or the difficulty in perceiving units in a nonnative language. Thus it is impossible to distinguish between these two alternative explanations based on the evidence we have thus far. The answer may lie in exploring the effects of cue strength manipulation in each native language with carefully controlled stimuli containing graded cues to clause boundaries.

Despite the reasons that Dutch- and English-learning infants treat pause-edited clause boundaries differently, the fact remains that these populations of infants do segment clauses from speech differently. If this finding were simply a by-product

\footnotetext{
${ }^{4}$ We recorded several additional Dutch speakers producing the passages we used in this study, and all produced small pitch resets relative to those seen in Seidl's (2007) study.
} 
of our Dutch recordings containing exceptionally small pitch resets at clause boundaries, this finding would be only mildly interesting. However, our stimuli directly reflect an inherent difference between the typical size of pitch resets in Dutch versus English. Thus, although we cannot say for sure why the Dutch infants treated the pause-edited stimuli differently in our experiments, it seems that this behavior is likely to be in some way reflective of how Dutch learners learn to perceive clause boundaries in their native language.

In sum, our results demonstrate that both Dutch- and English-learning 6month-olds segment prosodically marked clauses from speech, but they do so differently. We have offered two plausible accounts for why this is so. Regardless of which explanation further research supports, our findings suggest that languagespecific prosody plays an important role in early language acquisition. In addition, our findings pave the way for future studies investigating possible links between differences in the acoustic realization of large prosodic boundaries across languages, and the onset of word segmentation abilities in young infants.

\section{ACKNOWLEDGMENTS}

We thank Angela Khadar and the rest of the Nijmegen Baby Lab crew for help in running and recruiting participants. We are also grateful to the parents and children who participated in these experiments. Some of the data discussed in this article were presented at the 2005 ISCA Workshop on Plasticity in Speech Perception in London. Funding for this research was provided by an NWO Spinoza Prize entitled "Native and Non-native Listening" awarded to Anne Cutler and by NICHD R03 HD046463-0 awarded to Amanda Seidl.

\section{REFERENCES}

Aasland, W., \& Baum, S. (2003). Temporal parameters as cues to phrasal boundaries: A comparison of processing by left-hemisphere-damaged and right-hemisphere-damaged individuals. Brain and Language, 87, 385-399.

Bortfeld, H., Morgan, J. L, Golinkoff, R. M., \& Rathbun, K. (2005). Mommy and me: Familiar names help launch babies into speech stream segmentation. Psychological Science, 16, 298-304.

Christophe, A., Mehler, J., \& Sebastián-Gallés, N. (2001). Perception of prosodic boundary correlates by newborn infants. Infancy, 2, 385-394.

Cho, T., \& McQueen, J. (2005). Prosodic influences on consonant production in Dutch: Effects of prosodic boundaries, phrasal accent and lexical stress. Journal of Phonetics, 33, 121-157.

Collins, B., \& Mees, I. M. (1981). The phonetics of English and Dutch. Leiden, The Netherlands: Brill.

Fernald, A., \& Kuhl, P. K. (1987). Acoustic determinants of infant preference for motherese speech. Infant Behavior and Development, 10, 279-293.

Fougeron, C., \& Keating, P. A. (1997). Articulatory strengthening at edges of prosodic domains. Journal of the Acoustical Society of America, 101, 3728-3740. 
Friederici, A. D., Friedrich, M., \& Christophe, A. (2007). Brain responses in 4-month-old infants are already language specific. Current Biology, 17, 1-4.

Gout, A., Christophe, A., \& Morgan, J. L. (2004). Phonological phrase boundaries constrain lexical access: II. Infant data. Journal of Memory and Language, 51, 548-567.

Houston, D. M., Jusczyk, P. W., Kuijpers, C., Coolen, R., \& Cutler, A. (2000). Both Dutch and English learning 9-month-olds segment Dutch words from fluent speech. Psychonomic Bulletin \& Review, 7, 504-509.

Johnson, E. K. (2008). Infants use prosodically conditioned acoustic-phonetic cues to extract words from speech. Journal of the Accoustical Society of America, 123, EL 144-EL 148.

Johnson, E. K., \& Seidl, A. (2005, June). A cross-linguistic investigation of 6-month-olds' clause segmentation strategies. Poster presented at ISCA Workshop on Plasticity in Speech Perception, London.

Jusczyk, P. W. (1997). The discovery of spoken language. Cambridge, MA: MIT Press.

Jusczyk, P. W., \& Aslin, R. N. (1995). Infants' detection of the sound patterns of words in fluent speech. Cognitive Psychology, 29, 1-23.

Kemler Nelson, D. G., Hirsh-Pasek, K., Jusczyk, P. W., \& Wright-Cassidy, K. (1989). How prosodic cues in motherese might assist in language learning. Journal of Child Language, 16, 55-68.

Kooijman, V., Johnson, E. K., \& Cutler, A. (2008). Reflections on reflections of infant word recognition. In T. Friederici (Ed.) Early language development: Bridging brain and behaviour, series trends in language acquisition research (pp. 91-114). Amsterdam, The Netherlands: John Benjamins Publishing Company.

Kuijpers, C., Coolen, R., Houston, D., \& Cutler, A. (1998). Using the head-turning technique to explore cross-linguistic performance differences. In C. Rovee-Collier, L. Lipsitt, \& H. Hayne (Eds.), Advances in infancy research (Vol. 12, pp. 205-220). London: Ablex.

Morgan, J. L., \& Demuth, K. D. (Eds.). (1996). Signal to syntax: Bootstrapping from speech to grammar in early language acquisition. Mahwah, NJ: Lawrence Erlbaum Associates, Inc.

Nazzi, T., Dilley, L., Jusczyk, A. M., Shattuck-Hufnagel, S., \& Jusczyk, P. W. (2006). English-learning infants' segmentation of verbs from fluent speech. Language \& Speech, 48, 279-298.

Nazzi, T., Kemler Nelson, D. G., Jusczyk, P. W., \& Jusczyk, A. M. (2000). Six-month-olds' detection of clauses embedded in continuous speech: Effects of prosodic well-formedness. Infancy, 1 , 123-147.

Saffran, J. R., Werker, J. F., \& Werner, L. A. (2006). . In R. Siegler \& D. Kuhn (Eds.), Handbook of child development (6th ed., pp. 58-108). New York: Wiley.

Sanderman, A., \& Collins, R. (1997). Prosodic phrasing and comprehension. Language and Speech, 40, 391-409.

Schmitz, M., Höhle, B., \& Weissenborn, J. (2003, June). How pause length influences the perception of major syntactic boundaries in 6-month-old German infants. Paper presented at the conference of Generative Approaches to Language Acquisition (GALA), Groningen, The Netherlands.

Seidl, A. (2007). Infants' use and weighting of prosodic cues in clause segmentation. Journal of Memory and Language, 57, 24-48.

Seidl, A., \& Johnson, E. (2006). Infant word segmentation revisited: Edge alignment target extraction. Developmental Science, 9, 566-574.

Seidl, A., \& Johnson, E. K. (2008). Boundary alignment enables 11-months to segment vowel-initial words from speech. Journal of Child Language, 35, 1-24.

Selkirk, E. (1984). Phonology and syntax: The relation between sound and structure. Cambridge, MA: MIT Press.

Shukla, M., Nespor, M., \& Mehler, J. (2006). An interaction between prosody and statistics in the segmentation of fluent speech. Cognitive Psychology, 54, 1-32.

Soderstrom, M., Kemler Nelson, D. G., \& Jusczyk, P. W. (2005). Six-month-olds recognize clauses embedded in different passages of fluent speech. Infant Behavior and Development, 28, 87-94. 
Soderstrom, M., Seidl, A., Kemler Nelson, D., \& Jusczyk, P. W. (2003). The prosodic bootstrapping of phrases: Evidence from prelingual infants. Journal of Memory and Language, 49, 249-267.

Theissen, E. D., Hill, E. A., \& Saffran, J. R. (2005). Infant-directed speech facilitates word segmentation. Infancy, 7, 53-71.

Willems, N. (1982). English intonation from a Dutch point of view. Dordrecht, The Netherlands: Foris.

\section{APPENDIX}

Passages used in Experiments 1 and 2 with clauses (prosodically well-formed word strings) in boldface and nonclauses (prosodically ill-formed sequences) in italics.

Tante vraagt zich af wat de jongens eten. Koude pizza smaakt niet zo goed. Hun zus vindt dat lekker

'Aunt wonders what the boys eat/are eating. Cold pizza doesn't taste so good. Their sister likes that'

Het staat in de oven. De jongens eten koude pizza. Smaakt niet zo goed in de vroege ochtend.

'It's (placed) in the oven. The boys eat/are eating cold pizza. (It) doesn't taste so good in the early morning'

Passages used in Experiment 3 with clauses (prosodically well-formed word strings) in boldface and nonclauses (prosodically ill-formed sequences) in italics.

John doesn't know what rabbits eat. Leafy vegetables taste so good. They don't cost much either.

Many animals prefer green things. Rabbits eat leafy vegetables. Taste so good is rarely encountered. 